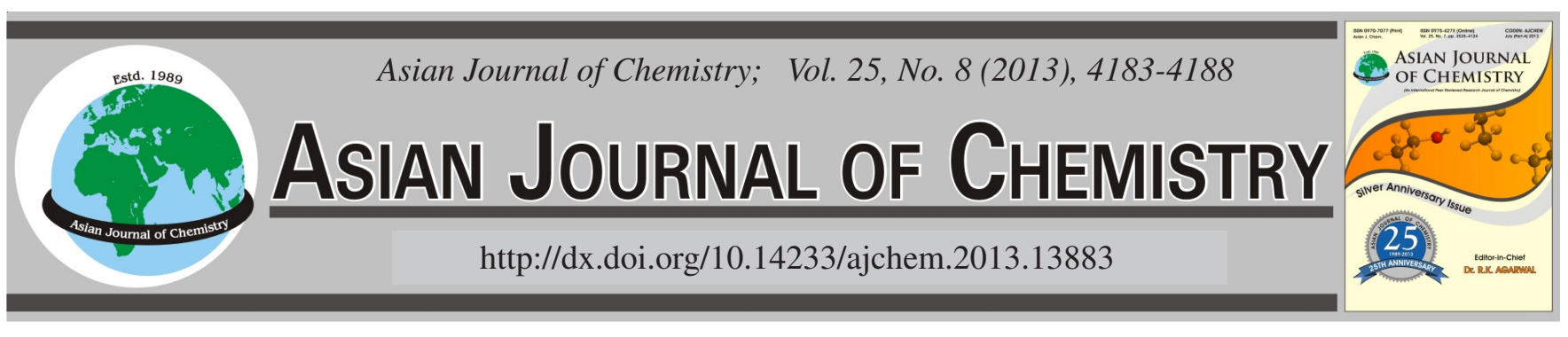

\title{
Antifungal Properties of Phenyl Fatty Hydroxamic Acids and Their Copper Complexes Synthesized Based on Canola and Palm Kernel Oils
} Md Jelas Haron ${ }^{1, *}$, Hossein Jahangirian $^{2, *}$, Mohd Halim Shah Ismail $^{2}$, Roshanak Rafiee-Moghaddam $^{3}$, Majid Rezayi $^{3}$,
Kamyar Shameli ${ }^{1}$, Yadollah Gharayebi ${ }^{1}$, Yadollah Abdollahi $^{4}$, Mazyar Peyda $^{2}$ and Behnam Mahdavi

\begin{abstract}
${ }^{1}$ Department of Chemistry, Faculty of Science, Universiti Putra Malaysia, 43400 UPM, Serdang, Selangor, Malaysia
${ }^{2}$ Department of Chemical and Environmental Engineering, Faculty of Engineering, Universiti Putra Malaysia, 43400 UPM, Serdang, Selangor, Malaysia

${ }^{3}$ School of Chemical Sciences and Food Technology, Faculty of Science and Technology, Universiti Kebangsaan Malaysia, 43600 UKM Bangi, Selangor, Malaysia

${ }^{4}$ Advanced Materials and Nanotechnology Laboratory, Institute of Advanced Technology, Universiti Putra Malaysia, UPM Serdang, 43400 Selangor, Malaysia
\end{abstract}

*Corresponding authors: E-mail: kamran.jahangirian@gmail.com; h.k@jahangirian.com; mdjelas@science.upm.edu.my

Key Words: Antifungal activity, Phenyl fatty hydroxamic acids, Copper phenyl fatty hydroxamate, Canola oil, Palm kernel oil.

ᄂ - - - - - - - - - - - - - - - - - - - - - - - -

\section{INTRODUCTION}

The biological activity of hydroxamic acids and their derivatives is one of the most important properties that were investigated in last half century. These compounds have been widely applied as cell-division factors ${ }^{1}$, tumour inhibitor drugs $^{2}$, antimalarial drugs ${ }^{3}$, growth factors ${ }^{4}$, enzyme inhibitors ${ }^{5}$, antibacterial agents ${ }^{6}$ and antifungal agents. Dudman ${ }^{7}$ applied sorbic hydroxamic acid as antifungal agent against the Aspergillus niger, Penicillium notatum, Botrytis cinerea and an unidentified Rhizopus species. He showed that sorbic hydroxamic acid is an antifungal agent which is effective over a wide $\mathrm{pH}$ range (3.6-9.2) and can be used as an additive in foods instead of sorbic acid. This is one of the early reports about antifungal properties of hydroxamic acids. Rao et al. ${ }^{8}$ investigated antifungal properties of many hydroxamic acids such as N,2'-diphenylaceto hydroxamic acid, 2,2'-diphenylaceto hydroxamic acid, 2-phenylaceto hydroxamic acid and their $\mathrm{Cu}(\mathrm{II}), \mathrm{Ni}(\mathrm{II})$ and $\mathrm{Co}(\mathrm{II})$ chelates against Alternaria alternata,
Fusarium oxysporum and Aspergillus flavus. They showed that the toxicity was augmented to a greater extent and the fungitoxicities of these metal chelates were found to be in the following order: $\mathrm{Cu}$ (II) $>\mathrm{Ni}$ (II) $>\mathrm{Co}$ (II) which is coincided with the order of the stability of the chelates. Rao later investigated the role of the stability of mixed-ligand complexes and its fungicidal potential ${ }^{9}$. Their results showed the mixed-ligand complexes were found to be more stable than binary complexes but the fungicidal activity of the mixed-ligand complexes did not improve significantly compared to binary complexes. Bravo and Lazo synthesized hydroxamic acids from 2,4-dihydroxy1,4-benzoxazin-3-one or 4-hydroxy-1,4-benzoxazin-3-one and used as antibacterial agents against the $S$. aureus and $E$. coli and as antifungal agents against Candida albicans ${ }^{10}$. Their results showed that the synthesized products have moderate antibacterial and antifungal properties. Later, Bravo and Lazo ${ }^{11}$ showed that natural hydroxamic acids and related compounds derived from 1,4-benzoxazin-3-one structures inhibit the growth of the alga Chlorella xanthella and the fungus Candida 
albicans. They then investigated the effect of chemical structure of the mentioned compound on antialgal and antifungal activities and found that the lipophilic character of the substituent in the aromatic ring and the electrophilic character of the hydroxamic function are suggested to be responsible for antialgal and antifungal activity, respectively. Agarwal et al. ${ }^{12}$ investigated antibacterial and antifungal properties of many of aryl alkyl hydroxamic acids. They showed that N-otolylbenzohydroxamic acid, acetohydroxamic acid, benzohydroxamic acid and salicylhydroxamic acid were highly active against fungi Candida albicans.

In the present investigation, we use the phenyl fatty hydroxamic acids synthesized from canola and palm kernel oils separately to prepare copper complex of phenyl fatty hydroxamic acids (Cu-PFHs) by reaction of the phenyl fatty hydroxamic acids and copper nitrate solution. The phenyl fatty hydroxamic acids and $\mathrm{Cu}$-PFHs were then evaluated as antifungal agents against the $C$. parapsilosis and $C$. albicans as fungal species of the yeast family and A. fumigatus as fungi by the well diffusion method. This is the first report about antifungal activity of phenyl fatty hydroxamic acids and $\mathrm{Cu}$-PFHs that prepared from palm kernel and canola oils.

\section{EXPERIMENTAL}

Phenyl hydroxylamine (PHA) was prepared using the method described by Vogel $^{13}$. Sodium hydroxide, zinc powder, sodium acetate, copper (II) nitrate, sodium chloride, ammonium chloride, nitrobenzene, nystatin and ketoconazole were purchased from Sigmaaldrich Co., USA. Lipozyme TL IM and was obtained from Novo Nordisk, Denmark. Hexane and absolute methanol were supplied by Systerm Co., Malaysia. Krystal brand of canola oil was supplied by FFM Berhad, Malaysia, palm kernel oils was supplied by Malaysian Palm Oil Board (MPOB), Malaysia, Mueller-Hinton agar (MHA) and and Potato Dextrose Agar (PDA) Difco brand were obtained from Voigt Global Distribution, USA.

Microorganisms: Candida parapsilosis (ATCC 22019) and Candida albicans (ATCC 10231) as fungal species of the yeast family and Aspergillus fumigatus as fungi were from clinical isolates which conformed to the Clinical and Laboratory Standards Institute, (CLSI, 2000).

Synthesis of phenyl fatty hydroxamic acids: Phenyl hydroxylaminolysis was carried out by shaking the mixture of the reactants, which contained $5 \mathrm{~g}$ phenyl hydroxylamine dissolved in $40 \mathrm{~mL}$ of distilled water, $5.5 \mathrm{~g}$ canola oil or $4.4 \mathrm{~g}$ palm kernel oil dissolved in $60 \mathrm{~mL}$ hexane and $480 \mathrm{mg}$ of the Lipozyme TL IM in a $400 \mathrm{~mL}$ flask sealed using Teflon film.
The mixture was shaken at $120 \mathrm{rpm}$ and $39^{\circ} \mathrm{C}$ in a water bath shaker for $72 \mathrm{~h}^{14}$. For separation of the products from the reaction mixture, first the enzyme was filtered and the filtrate was transferred into a separation funnel then aqueous phase were separated from organic phase. The organic phase in the funnel was shaken with $40 \mathrm{~mL}$ distilled water for removal of glycerol residue and then with two times $60 \mathrm{~mL} \mathrm{HCl}$ solution (2 M) for removal of the unreacted phenyl hydroxylamine. Hexane was then removed by a rotary evaporator to obtain mixture of phenyl fatty hydroxamic acids and unreacted oil. Finally phenyl fatty hydroxamic acids were extracted by using $80 \mathrm{~mL}$ absolute methanol from the unreacted oil and then recovered by a rotary evaporator. Scheme-I shows the equation of phenyl hydroxylaminolysis.

Preparation of Cu-PFHs: Copper complexation of phenyl fatty hydroxamic acids was carried out by stirring mixture of phenyl fatty hydroxamic acids and copper nitrate solutions in biphasic medium. For this purpose $0.5 \mathrm{~g}$ of phenyl fatty hydroxamic acids dissolved in $80 \mathrm{~mL}$ hexane was mixed with $250 \mathrm{~mL}$ of copper nitrate solution buffered by sodium acetate at $\mathrm{pH}=6.3\left(\left[\mathrm{Cu}^{2+}\right) c a .10 \mathrm{mM}\right)$. The mixture was stirred at $300 \mathrm{rpm}$ and $30^{\circ} \mathrm{C}$ for $20 \mathrm{~min}$ and organic phase was separated from aqueous phase by separation funnel. For maximum complex formation the phenyl fatty hydroxamic acids in organic phase were reacted with $250 \mathrm{ml}$ of copper nitrate solution again. Finally the organic phase was separated from aqueous phase and $\mathrm{Cu}-\mathrm{PFH}$ were obtained after removing hexane by a rotary evaporator. $\mathrm{Cu}-\mathrm{PFH}$ based on canola oil were deep green liquid while $\mathrm{Cu}$-PFHs based on palm kernel oil were deep green semi solid and pasty.

Evaluation of antifungal activity: Antifungal activities of phenyl fatty hydroxamic acids and $\mathrm{Cu}$-PFHs were evaluated by the disc diffusion method using MHA and PDA agars with determination of inhibition zones in millimeter $(\mathrm{mm})$. $C$. parapsilosis, $C$. albicans and A. fumigatus were used for the antifungal assay. In the disc diffusion method, the sterile paper discs (6 $\mathrm{mm}$ in diameter) were impregnated with $8,12,16$ and $20 \mu \mathrm{L}$ of phenyl fatty hydroxamic acids and $\mathrm{Cu}-\mathrm{PFHs}$ solution (concentration, $50 \%$ in hexane; the final concen-trations were $4,6,8$ and $10 \mu \mathrm{g} / \mathrm{disc}$ ) separately and left to dry at $37^{\circ} \mathrm{C}$ for $24 \mathrm{~h}$ in a sterile condition. The surface of MHA and PDA agars agar in the each of the test plates were completely inoculated by the equal amount of fungus using a sterile swab, which was steeped in the prepared suspension of fungus. Finally, the impregnated paper discs were put on the surface of agar plates and were incubated at $37^{\circ} \mathrm{C}$ for $48 \mathrm{~h}$. After the end of incubation period, the diameter of the growth inhibition

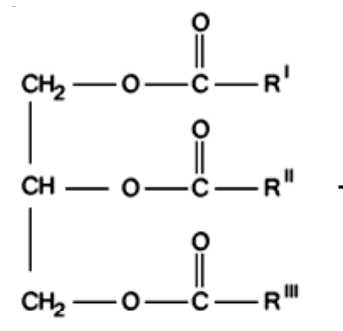

Triglyceride

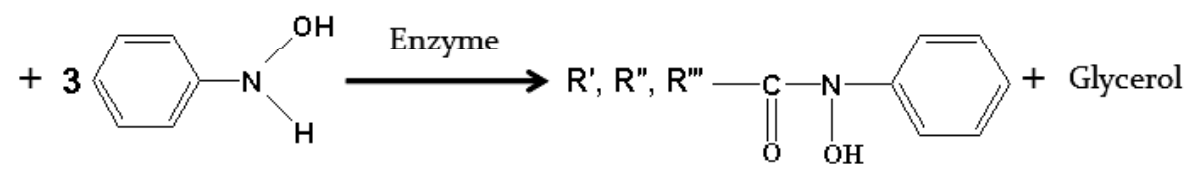

PHA

PFHAs

Scheme-I: Reaction equation of phenylhydroxylaminolysis of triglycerides. Enzyme = Lipozyme. R', R" and R"' = hydrocarbon chains of fatty acids 
zones was measured. The fungi suspensions were prepared by making a saline suspension of isolated colonies selected from the 18-24 h of agar plate. The suspension was adjusted to match the tube of $0.5 \mathrm{McFarland}$ turbidity standard using the spectrophotometer of $600 \mathrm{~nm}$, which equals to $1.5 \times 10^{8}$ colony-forming units $(\mathrm{CFU}) / \mathrm{mL}$. Canola oil, palm kernel oil hexane and copper solution were used as the negative standards while nystatin and ketoconazole antifungal drugs were used as the positive standards in order to control the sensitivity of the antifungal activity. The copper solution for negative control was prepared similar to complexation condition of phenyl fatty hydroxamic acids; $80 \mathrm{~mL}$ hexane (without phenyl fatty hydroxamic acids) was mixed with $250 \mathrm{~mL}$ of copper nitrate solution buffered by sodium acetate at $\mathrm{pH}=6.3\left(\left[\mathrm{Cu}^{2+}\right] c a .10 \mathrm{mM}\right)$. The mixture was stirred at $300 \mathrm{rpm}$ and $30{ }^{\circ} \mathrm{C}$ for $20 \mathrm{~min}$ then organic phase was separated from aqueous. All the tests were done in three replicates.

Characterization: The amount of phenyl fatty hydroxamic acids was estimated based on nitrogen content, determined by CHN analyzer (model 932 LECO, USA). Perkin-Elmer 1650 Infrared Fourier Transform Spectrometer was used for recording FTIR spectra. ${ }^{1} \mathrm{H}$ nuclear magnetic resonance $\left({ }^{1} \mathrm{H}\right.$ NMR) spectra were recorded using the NMR Spectrophotometer (Model 400 Joel Ltd., Tokyo, Japan). Shimadzu UV-VIS spectrophotometer (Model UV-1650 PC) was used for recording UV-Vis spectra.

\section{RESULTS AND DISCUSSION}

Antibacterial activity: Inhibition zone values were obtained for the phenyl fatty hydroxamic acids and $\mathrm{Cu}-\mathrm{PFHs}$ tested against the $C$. parapsilosis, C. albicans and A. fumigatus by disc diffusion methods. The values of the inhibition zones are presented in Table-1. The $t$-test was used to determine significance of the experimental results with a similar dosage of the antibacterial agents. The data indicate that the antifungal activity of both phenyl fatty hydroxamic acids and $\mathrm{Cu}-\mathrm{PFHs}$ against the $C$. albicans are significantly higher than against the A. fumigatus (phenyl fatty hydroxamic acids, $p<0.01$; $\mathrm{Cu}$-PFHs, $p<0.001$ for those based on canola oil and phenyl fatty hydroxamic acids, $p<0.002$; Cu-PFHs, $p<0.0005$ for those based on palm kernel oil) and lower than against the $C$. parapsilosis (phenyl fatty hydroxamic acids, $p<0.001$; $\mathrm{Cu}$-PFHs, $p<0.02$ for those based on canola oil and phenyl fatty hydroxamic acids, $p<0.1$; Cu-PFHs, $p<0.1$ for those based on palm kernel oil). Also antifungal activity of phenyl fatty hydroxamic acids and $\mathrm{Cu}-\mathrm{PFH}$ increases when their concentrations increase. The results also indicate that copper complexation has increased the antifungal activity of phenyl fatty hydroxamic acids from canola oil (A. fumigatus, $p<0.1$; C. parapsilosis, $p<0.01 ; C$. albicans, $p<0.002)$ and phenyl fatty hydroxamic acids from palm kernel oil (A. fumigatus, $p$ $<0.2$; C. parapsilosis, $p<0.002 ; C$. albicans, $p<0.002)$. This phenomenon was occurred due to synergistic combination of the coordinated copper ion with phenyl fatty hydroxamic acids. Rao et al. ${ }^{8}$ reported similar results for antifungal properties of many hydroxamic acids and their $\mathrm{Cu}(\mathrm{II})$ chelates against the Alternaria alternata, Fusarium oxysporum and Aspergillus flavus.

The results also indicate that the antifungal activity against A. fumigatus, C. parapsilosis and C. albicans for both phenyl fatty hydroxamic acids and $\mathrm{Cu}-\mathrm{PFH}$ based on canola oil are significantly stronger than respective phenyl fatty hydroxamic acids (A. fumigatus, $p<0.002 ; C$. parapsilosis, $p<0.002 ; C$. albicans, $p<0.1)$ and $\mathrm{Cu}$-PFHs $(A$. fumigatus, $p<0.001 ; C$. parapsilosis, $p<0.001$; $C$. albicans, $p<0.2)$ based on palm kernel oil. This phenomenon occurred could be due to the

\begin{tabular}{|c|c|c|c|c|}
\hline \multicolumn{5}{|c|}{$\begin{array}{l}\text { TABLE-1 } \\
\text { INHIBITION OF GROWTH (MEAN } \pm \text { SD, mm, } \mathrm{n}=3 \text { ) OF A. fumigatus, } C \text {. parapsilosis AND C. albicans } \\
\text { BY PFHAs, Cu-PFHs, NYSTATIN AND KETOCONAZOLE USING DISC DIFFUSION METHOD }\end{array}$} \\
\hline Compound & Concentration ( $\mu \mathrm{g} / \mathrm{disc})$ & $\begin{array}{c}\text { Growth inhibition on } A \text {. } \\
\text { fumigatus }\end{array}$ & $\begin{array}{l}\text { Growth inhibition on } \\
\text { C. parapsilosis }\end{array}$ & $\begin{array}{l}\text { Growth inhibition on } \\
\text { C. albicans }\end{array}$ \\
\hline \multirow{3}{*}{ PFHAs from canola oil } & 4 & $11.5 \pm 0.6$ & $17.7 \pm 0.9$ & $12.2 \pm 0.9$ \\
\hline & 6 & $12.1 \pm 0.7$ & $18.8 \pm 0.8$ & $13.0 \pm 0.7$ \\
\hline & 8 & $12.8 \pm 0.8$ & $20.0 \pm 0.9$ & $15.1 \pm 0.8$ \\
\hline \multirow{4}{*}{$\mathrm{Cu}-\mathrm{PFH}$ from canola oil } & 4 & $12.8 \pm 0.5$ & $20.2 \pm 0.8$ & $17.2 \pm 0.8$ \\
\hline & 6 & $13.5 \pm 0.7$ & $21.6 \pm 0.8$ & $18.7 \pm 0.6$ \\
\hline & 8 & $14.1 \pm 0.6$ & $22.5 \pm 1.0$ & $19.7 \pm 0.8$ \\
\hline & 10 & $15.0 \pm 0.8$ & $23.7 \pm 0.8$ & $21.0 \pm 1.0$ \\
\hline \multirow{3}{*}{$\begin{array}{l}\text { PFHAs from palm kernel } \\
\text { oil }\end{array}$} & 4 & $9.4 \pm 0.3$ & - & - \\
\hline & 6 & $9.9 \pm 0.4$ & - & - \\
\hline & 8 & $10.7 \pm 0.3$ & - & - \\
\hline \multirow{4}{*}{$\begin{array}{l}\mathrm{Cu}-\mathrm{PFHs} \text { from palm } \\
\text { kernel oil }\end{array}$} & 4 & $10.5 \pm 0.5$ & & \\
\hline & 6 & $11.0 \pm 0.5$ & & \\
\hline & 8 & $11.7 \pm 0.4$ & & \\
\hline & 10 & $12.3 \pm 0.7$ & $21.2 \pm 0.8$ & $20.1 \pm 0.9$ \\
\hline \multicolumn{5}{|c|}{ Control positive } \\
\hline \multirow{4}{*}{ Nystatin } & 10 & $6.7 \pm 0.4$ & $11.2 \pm 0.4$ & $9.1 \pm 0.5$ \\
\hline & 20 & $7.1 \pm 0.4$ & $12.8 \pm 0.5$ & $11.2 \pm 0.7$ \\
\hline & 80 & - & - & $13.9 \pm 0.6$ \\
\hline & 100 & $14.8 \pm 0.7$ & - & - \\
\hline \multirow{3}{*}{ Ketoconazole } & 10 & $10.3 \pm 0.4$ & - & - \\
\hline & 20 & $13.5 \pm 0.9$ & - & - \\
\hline & 100 & $25.7 \pm 1.0$ & - & - \\
\hline
\end{tabular}


higher mobility of the phenyl fatty hydroxamic acids and $\mathrm{Cu}$-PFHs obtained from canola oil than those obtained from palm kernel oil due to difference in unsaturated hydrocarbon in their alkyl branches. Also the mentioned phenomena indicates that the antifungal activity of phenyl fatty hydroxamic acids and $\mathrm{Cu}$-PFHs based on both canola and palm kernel oils in vivo might be more pronounced than in vitro due to higher mobility of the compounds in vivo to in vitro.

Comparing the antifungal activity of phenyl fatty hydroxamic acids and $\mathrm{Cu}-\mathrm{PFHs}$ with commercial antibiotic such as nystatin and ketoconazole (Table-1) indicate that antifungal activity of phenyl fatty hydroxamic acids and $\mathrm{Cu}-\mathrm{PFHs}$ against the A. fumigatus, $C$. parapsilosis and C. albicans definitely are stronger than antifungal activity of nystatin $(p<$ $0.0005)$. The antifungal activity of phenyl fatty hydroxamic acids and $\mathrm{Cu}-\mathrm{PFH}$ against the $A$. fumigatus are stronger than antifungal activity of ketoconazole (phenyl fatty hydroxamic acids, $p<0.001$; Cu-PFHs, $p<0.0005$ for those based on canola oil and phenyl fatty hydroxamic acids, $p<0.02$; $\mathrm{Cu}-\mathrm{PFHs}, p<0.01$ for those based on palm kernel oil). Finally the results showed that (data were not shown) hexane, copper solution, phenyl hydroxylamine, canola oil and palm kernel oil were not active as antifungal against the A. fumigatus, $C$. parapsilosis and $C$. albicans when they were tested at dosage of $20 \mu \mathrm{g} / \mathrm{disc}$ as control negative.

\section{Quantification and characterization of phenyl fatty hydroxamic acids}

Elemental analysis: The results of elemental analysis by the $\mathrm{CHN}$ analyzer show that the nitrogen content in the synthesized phenyl fatty hydroxamic acids and $\mathrm{Cu}$-PFHs from the canola oil were 3.83 and $3.479 \%$, respectively. This indicates that there were $2.74 \mathrm{mmol}$ of phenyl fatty hydroxamic acid groups and $1.24 \mathrm{mmol}$ of copper phenyl fatty hydroxamate in $1 \mathrm{~g}$ of each of the product.

Fourier transform infrared spectroscopy: The absorption peaks of the FTIR spectra of phenyl fatty hydroxamic acids and $\mathrm{Cu}-\mathrm{PFH}$ base on canola oil are shown in Table-2.

\begin{tabular}{ccl} 
& \multicolumn{2}{c}{ TABLE-2 } \\
& FTIR SPECTRAL ASSIGNMENTS OF PFHAs AND \\
Cu-PFHs BASE ON CANOLA OIL
\end{tabular}

In phenyl fatty hydroxamic acids spectrum the peaks at $3100-2800 \mathrm{~cm}^{-1}$ correspond to O-H stretching that was wider and lower in intensity compared to free $\mathrm{O}-\mathrm{H}$ probably due to formation of intermolecular hydrogen bonding. The peaks at 3068 and $3008 \mathrm{~cm}^{-1}$ correspond to $=\mathrm{C}-\mathrm{H}$ stretching and the peaks at 2924 and $2854 \mathrm{~cm}^{-1}$ correspond to $-\mathrm{C}-\mathrm{H}$ stretching for the long chain of alkyl. The peaks at 1739 and $1708 \mathrm{~cm}^{-1}$ correspond to $\mathrm{C}=\mathrm{O}$ stretching which splits to two branches and shifted to upper frequencies due to Fermi resonance ${ }^{15}$. In addition the peaks at 1477 and $1437 \mathrm{~cm}^{-1}$ correspond to $\mathrm{C}=\mathrm{C}$ stretching, the peak at $1299 \mathrm{~cm}^{-1}$ corresponds to $=\mathrm{C}-\mathrm{N}$ stretching and finally the peaks at 761 and $682 \mathrm{~cm}^{-1}$ correspond to mono substitution of aromatic ring.

In $\mathrm{Cu}$-PFHs spectrum the peaks at 3067 and $3006 \mathrm{~cm}^{-1}$ correspond to $=\mathrm{C}-\mathrm{H}$ stretching and the peaks at 2923 and 2854 $\mathrm{cm}^{-1}$ correspond to $-\mathrm{C}-\mathrm{H}$ stretching for the long chain alkyl and the peak at $1742 \mathrm{~cm}^{-1}$ corresponds to $\mathrm{C}=\mathrm{O}$ stretching. This peak is single branch due to complexation and dative bonding from lone pair of electrons of oxygen and copper. In addition the peaks at 1475 and $1440 \mathrm{~cm}^{-1}$ correspond to $\mathrm{C}=\mathrm{C}$ stretching, the peak at $1299 \mathrm{~cm}^{-1}$ corresponds to $=\mathrm{C}-\mathrm{N}$ stretching, the peak at $1164 \mathrm{~cm}^{-1}$ corresponds to $-\mathrm{C}-\mathrm{O}$ stretching that was appeared due to connecting of copper to $\mathrm{C}=\mathrm{O}$ and finally the peaks at 761 and $682 \mathrm{~cm}^{-1}$ correspond to mono substitution of aromatic ring. The FTIR spectra of phenyl fatty hydroxamic acids and $\mathrm{Cu}$-PFHs base on palm kernel oil are almost similar to the spectra of phenyl fatty hydroxamic acids and $\mathrm{Cu}$-PFHs based on canola oil.

UV-visible spectroscopy of Cu-PFHs: Comparison of UV-visible spectra of canola oil, phenyl hydroxylamine, phenyl fatty hydroxamic acids and $\mathrm{Cu}-\mathrm{PFH}$ in Fig. 1 show that $\mathrm{Cu}$-PFHs based on canola oil was successfully formed.

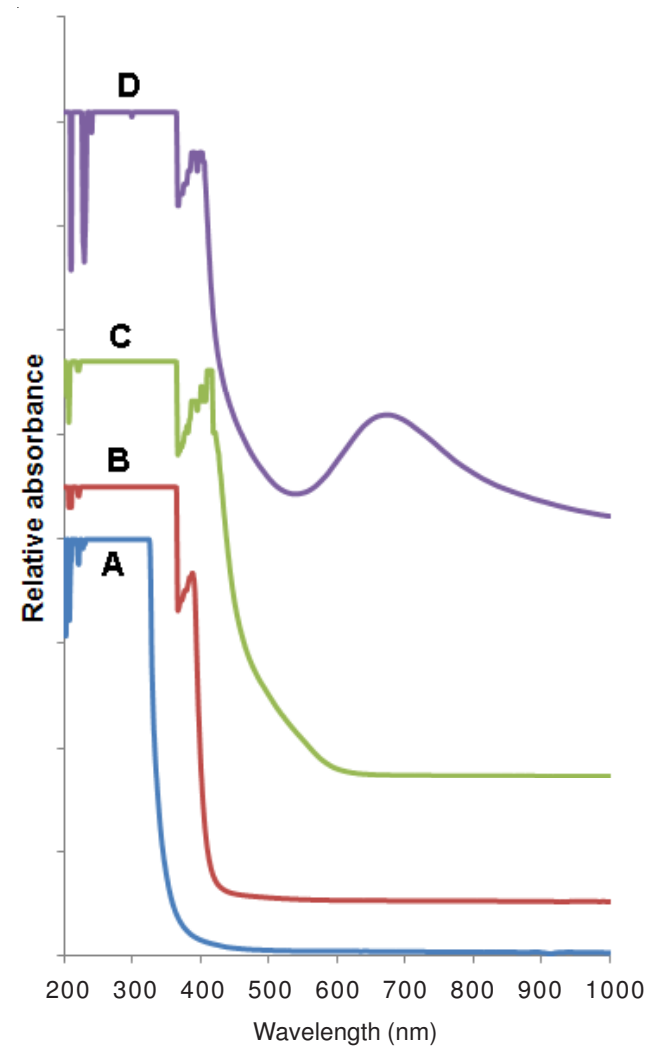

Fig. 1. Comparison of UV-visible spectra of (A) canola oil, (B) phenyl hydroxylamine, (C) phenyl fatty hydroxamic acids and (D) Cu-PFHs. The concentration of all compounds, $50 \mathrm{mM}$ 
Firstly no distinct absorbance peak is seen in the spectrum of canola oil (A). In the spectrum of phenyl hydroxylamine (B), the peak appeared at $390 \mathrm{~nm}$ ought to be from the hydroxyl amine functional group on benzene ring due to $n \rightarrow \pi *$ electronic transition. In the spectrum of phenyl fatty hydroxamic acids (C), the mentioned peak was shifted to upper region (415 $\mathrm{nm}$ ) due to coupling of carbonyl group and forming of hydroxamic acid group. Finally in the spectrum of $\mathrm{Cu}-\mathrm{PFHs}$ (D), the mentioned peak was shifted to lower region $(410 \mathrm{~nm})$ due to coupling of copper for formation of copper hydroxamate. Also in $\mathrm{Cu}-\mathrm{PFHs}$ spectrum (D), another peak has appeared in the visible region of $673 \mathrm{~nm}$ due to the coordinate covalent bonds between copper and oxygen atoms of phenyl fatty hydroxamic acids. Similarly, consideration of UV-visible spectra of palm kernel oil, phenyl hydroxylamine, phenyl fatty hydroxamic acids and $\mathrm{Cu}$-PFHs based on palm kernel oil (figure was not shown) indicates that the $\mathrm{Cu}-\mathrm{PFH}$ complex was also successfully formed. In addition, the obtained $\mathrm{Cu}$ $\mathrm{PFHs}$ are green and this is in agreement with green colour of copper complex of fatty hydroxamic acids (Cu-FHAs) base on palm oil reported by Suhendra et al. ${ }^{16}$ and green colour of $\mathrm{Cu}$-FHAs based on canola oil as reported by our group ${ }^{17}$.

${ }^{1} \mathbf{H}$ Nuclear magnetic resonance $\left({ }^{1} \mathbf{H}\right.$ NMR): ${ }^{1} \mathrm{H}$ NMR spectra of phenyl fatty hydroxamic acids and $\mathrm{Cu}$-PFHs showed that there was no signal shifting due to copper complexation so in this section we only described ${ }^{1} \mathrm{H}$ NMR spectra of phenyl fatty hydroxamic acids.

${ }^{1} \mathrm{H}$ NMR spectra of phenyl fatty hydroxamic acids based on the canola oil: The formulation of phenyl hydroxylamine and the major phenyl fatty hydroxamic acids based on the canola oil are presented in Fig. 2. ${ }^{1} \mathrm{H}$ NMR spectra of the product showed the signals at a $(0.92,0.93$ and $0.93 \mathrm{ppm}), \mathrm{b}$ (1.30 and $1.33 \mathrm{ppm}), \mathrm{c}(1.63,1.65$ and $1.66 \mathrm{ppm}), \mathrm{d}(2.04$ and $2.06 \mathrm{ppm})$, e (2.33 and $2.35 \mathrm{ppm}), \mathrm{f}(2.81,2.83$ and $2.84 \mathrm{ppm})$ and $g(5.39,5.40,5.41 \mathrm{ppm})$ corresponding to the alkyl branch hydrogens of the phenyl fatty hydroxamic acids that are shown in Fig. 2. These signals were confirmed for the alkyl branch hydrogens of oleic acid, linoleic acid and linolenic acid. In addition Takenaka et al. ${ }^{18}$ reported the ${ }^{1} \mathrm{H}$ NMR signals of the hydrogen of the aromatic ring of phenyl hydroxylamine appeared at 6.96-7.01 ppm (labeled by i, j, k) and 7.26-7.28 ppm (labeled by h, L). However ${ }^{1} \mathrm{H}$ NMR spectra of the phenyl fatty hydroxamic acids based on the canola oil in this study showed these signals shifted to the upper regions at 7.37-7.53 ppm (labeled by i, j, k) and 8.20-8.33 ppm (labeled by h, L).

A)

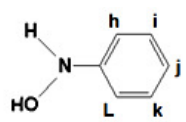

B )

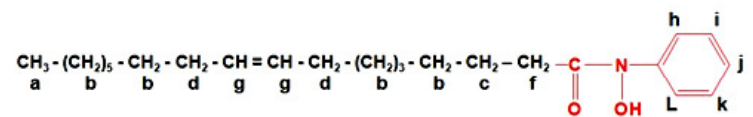

c)

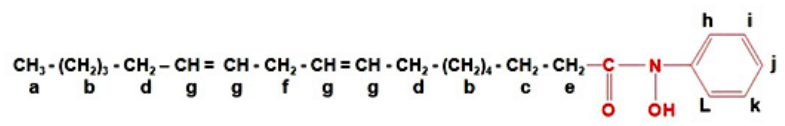

Fig. 2. Formulation of (A) phenyl hydroxylamine, (B) phenyl oleohydroxamic acid and (C) phenyl linoleohydroxamic acid
${ }^{1}$ H NMR spectra of phenyl fatty hydroxamic acids based on the palm kernel oil: ${ }^{1} \mathrm{H}$ NMR spectra of the product showed the signals at a $(0.88,0.90$ and $0.91 \mathrm{ppm}), \mathrm{b}(1.27$, 1.29 and $1.30 \mathrm{ppm}), \mathrm{c}(1.62,1.65$ and $1.67 \mathrm{ppm}), \mathrm{d}(2.34$, 2.36 and $2.37 \mathrm{ppm}$ ), corresponding to the alkyl branch hydrogens of the phenyl fatty hydroxamic acids that are shown in Fig. 3. As mentioned in section 2.2.4.1 the signals of the hydrogen of the aromatic ring of phenyl hydroxylamine should appear at 6.96-7.01 ppm (labeled by f, g, h) and 7.26-7.28 ppm (labeled by e, i $)^{20}$. However ${ }^{1} \mathrm{H}$ NMR spectra of the phenyl fatty hydroxamic acids based on the palm kernel oil in this study showed these signals shifted to the upper regions at 7.277.59 ppm (labeled by f, g, h) and 8.17 - 8.34 ppm (labeled by e, i).

A)
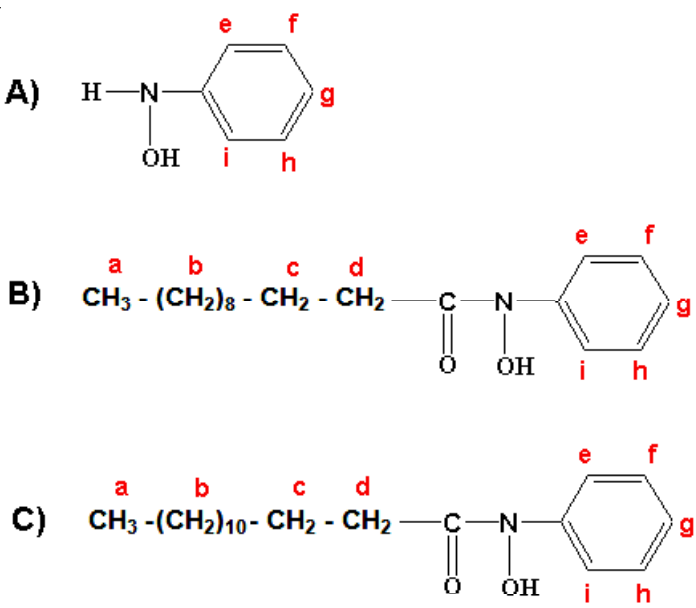

Fig. 3. Formulation of (A) phenyl hydroxylamine, (B) phenyl laureohydroxamic acid and $(\mathrm{C})$ phenyl myristohydroxamic acid

\section{Conclusion}

This paper is the first report which describes the antifungal activity of phenyl fatty hydroxamic acids and Cu-PFHs based on palm kernel and canola oil. Among the advantages of using this products are the method of preparation of the phenyl fatty hydroxamic acids ligand and its copper complex is simple using vegetable oils which are cheap and easily available. In addition, utilization of enzymatic reaction in the phenyl fatty hydroxamic acids preparation has the advantages of good saving in energy towards achieving green chemistry. Elemental analysis, UV-VIS, FTIR spectra and ${ }^{1} \mathrm{H}$ NMR spectra showed that phenyl fatty hydroxamic acids and $\mathrm{Cu}$-PFHs were successfully produced. In this investigation we showed the antifungal activity of phenyl fatty hydroxamic acids were increased by copper complexation and while phenyl fatty hydroxamic acids and $\mathrm{Cu}-\mathrm{PFH}$ concentration increase. The antifungal activity of $\mathrm{Cu}-\mathrm{PFH}$ and phenyl fatty hydroxamic acids based on canola oil are stronger than the respective compounds based on palm kernel oil. The most important finding of this investigation is that the antifungal activity of phenyl fatty hydroxamic acids and $\mathrm{Cu}-\mathrm{PFH}$ against the $A$. fumigatus, $C$. parapsilosis and $C$. albicans are significantly higher than antifungal activity of nystatin as antifungal drug and moreover the antifungal activity of phenyl fatty hydroxamic acids and $\mathrm{Cu}$-PFHs against the $A$. fumigatus is significantly higher than antifungal activity of ketoconazole as antifungal drugs. 


\section{REFERENCES}

1. B.R. Byers, M.V. Powell and C.E. Lankford, J. Bacteriol., 93, 286 (1967).

2. J. Holms, K. Mast, P. Marcotte, I. Elmore, J. Li, L. Pease, K. Glaser, D. Morgan, M. Michaelides and S. Davidsen, Bioorg. Med. Chem. Lett., 11, 2907 (2001).

3. A. Tsafack, J. Golenser, J. Libman, A. Shanzer and Z.I. Cabantchik, Mol. Pharmacol., 47, 403 (1995).

4. G.A. Snow, Bacteriol. Rev., 34, 99 (1970).

5. C. Xue, X. He, L.R. Corbett, J. Roderick, R.Z. Wasserman, R. Liu, D.B. Jaffee, B.M. Covington, M. Qian, M.J. Trzaskos, C.R. Newton, LR. Magolda, R.R. Wexler and P.C. Decicco, J. Med. Chem., 44, 3351 (2001).

6. C. Apfel, D.W. Banner, D. Bur, M. Dietz, T. Hirata, C. Hubschwerlen, H. Locher, M.G.P. Page, W. Pirson, G. Rossé and J. Specklin, J. Med. Chem., 43, 2324 (2000)

7. W.F. Dudman, Appl. Microbiol., 11, 362 (1963).

8. M.J. Rao, B. Sethuram and T.N. Rao, J. Inorg. Biochem., 24, 155 (1985).

9. M.J. Rao, J. Inorg. Biochem., 46, 207 (1992).
10. H.R. Bravo and W. Lazo, Phytochemistry, 33, 569 (1993).

11. H.R. Bravo and W. Lazo, J. Agric. Food Chem., 44, 1569 (1996).

12. H. Agarwal, O.P. Agarwal, R. Karnawat and I.K.P.S. Sharma, Int. J. Appl. Biol. Pharm. Technol., 1, 1293 (2010).

13. A.I. Vogel, A.R. Tatchell, B.S. Furnis, A.J. Hannaford and P.W.G. Smith, Text Book of Practical Organic Chemistry, Longman; London and New York, p. 722 (1978).

14. H. Jahangirian, M.J. Haron, S. Silong and N.A. Yusof, J. Oleo Sci., 60 , 281 (2011)

15. D.L. Pavia, G.M. Lampman and G.S. Kriz, Introduction to Spectroscopy, Tomson Learning Inc.: Washington, USA, edn. 3, p. 71 (2001).

16. D. Suhendra, W.M.Z. Wan Yunus, M.J. Haron, M. Basri and S. Silong, J. Oleo Sci., 54, 33 (2005).

17. H. Jahangirian, M.J. Haron, S. Silong and N.A. Yusof, Asian J. Chem., 23, 3371 (2011).

18. M.S.F. Lie, K. Jie, M.K. Pasha and M.S. Alam, Lipids, 32, 1041 (1997).

19. M.S.F. Lie and K. Jie, Eur. J. Lipid Sci. Technol., 103, 628 (2001).

20. Y. Takenaka, T. Kiyosu, J. Choi, T. Sakakura and H. Yasuda, Green Chem., 11, 1385 (2009). 